\title{
'Teaching the Way I Was Taught': We Can and Should Do Better
}

\author{
Lorraine Bennett* \\ Centre for Learning Innovation and Professional Practice, Federation University Australia, Ballarat, Australia \\ *Corresponding author: lorraine.bennett@ federation.edu.au
}

Received September 05, 2014; Revised October 05, 2014; Accepted October 12, 2014

\begin{abstract}
Consideration of the quality of higher education is a complex and multifaceted issue. A number of stakeholders contribute to this debate and have very diverse perspectives and distinctive opinions on what constitutes quality of, and quality in, higher education and how it should be described, fostered, measured and reported. Discussion at the meta-level tends to focus on aspects such as: national quality frameworks and standards; rankings; benchmarking; and, graduate employment outcomes. Over the past decade, in Australia and in other countries with similar higher education ideologies and structures, there have been concerted efforts to identify and map characteristics of teaching effectiveness and attributes of an effective teacher to better understand how these factors contribute to quality of higher education. Some research studies and educational commentators nominate the capacity and effectiveness of the teacher as critical components in providing a quality education experience. The irony is that in Australian universities, and similarly in higher education in many other countries, a tertiary teaching qualification is not required for employment as a teacher/lecturer in universities. Consequently, for many of our universities the practice of 'teaching the way I was taught' has become the default approach to engaging with increasingly diverse and mobile higher education student populations. This paper describes how a personalised Graduate Certificate in Education (Tertiary Teaching), for newly appointed and early career tertiary teachers, taken post-employment, is addressing this issue to some extent. However, in the final analysis the questions that need to be asked are: 'What is the impact on the quality of higher education of not requiring our teaching staff to have a tertiary teacher education qualification as a pre-requisite for employment?' and 'Are we doing a disservice to our students by not requiring university teachers to have appropriate tertiary teacher education preparation?
\end{abstract}

Keywords: quality of higher education, staff professional learning and development, tertiary teaching qualification, science of learning

Cite This Article: Lorraine Bennett, “ 'Teaching the Way I Was Taught': We Can and Should Do Better." American Journal of Educational Research, vol. 2, no. 10 (2014): 911-918. doi: 10.12691/education-2-10-10.

\section{Introduction}

Over the past decade, particularly in Australia and in many other comparable international higher education sectors, the issue of quality of higher education has been interrogated, investigated and dissected from a number of angles. The fact that the quality of higher education can be viewed from so many perspectives highlights the complexity and difficulty of reaching a common understanding of what quality higher education looks like and how to go about ensuring that it is achieved.

The quality higher education agenda pursued by many governments is typically couched in terms of regulation, compliance, national standards and frameworks, measurements and threshold outcomes. In Australia, the Tertiary Education Quality and Standards Agency (TEQSA) [1], assesses both the compliance and quality of higher education providers. Registration and assessment of performance is based on a Higher Education Standards Framework [2]. This Framework is currently undergoing an extensive, independent review. The Qualifications
Standards within the Standards Framework are aligned with the Australian Qualification Framework policy and states that a 'teacher should have at least one degree above the one that they are teaching' [3]. However, this does not necessarily mean a teaching qualification. Through the Review Panel's consultation process the debate about the need for a tertiary teaching qualification, has been raised and acknowledged by the panel as an issue requiring further analysis [4]. It is unclear at this stage as to whether the panel report will take a mandatory or optional approach to this requirement.

While the scenario described above relates to Australian higher education it resonates with the scrutiny and debate that many other national government authorities and higher education quality agencies are experiencing and reporting [5,6]. The wider public and in particular parents, have yet another view on the quality of higher education. The public tends to focus on value for money and accountability. In recent times the community's increased scrutiny of the quality of higher education is directly linked to how their taxes are being spent. The community seeks evidence of quality outcomes from academic activities and research that significantly 
contributes to society's well-being [7]. For a number of years, parents report that they want their children to become qualified for a career as a result of graduating from university. They expect our universities to deliver world class programs, enabling their children to receive a quality education and develop the skills and knowledge necessary to lead productive and enriched lives [8].

Employers have yet another view of quality higher education. They want work-ready graduates; employees who can quickly integrate and contribute to their workplace by having the necessary skills and industry knowledge to perform their roles effectively and efficiently. In particular, employers want graduates with drive and commitment, who have excellent interpersonal/communication skills, and analytical and problem solving abilities [9].

Generally speaking, university senior managers adopt a similar view to quality of higher education as evidenced in government policies and practice. They are primarily interested in quality, as it relates to governance and fiscal matters. Their conversations around the quality of higher education centre on metrics such as enrolment numbers, attrition rates, percentage of full-fee paying and international students, growing new markets, and casualisation of the teaching workforce. Issues related to the quality of teaching and teacher qualifications are primarily considered within a framework of student satisfaction and the impact on student retention figures [10].

Another key stakeholder group interested in the quality of higher education is students. Students focus on the quality of the university experience. This generally extends beyond their participation in formal courses. They assess quality in terms of, not only the quality of the teaching and teachers, but the quality of the social, sport and recreational activities accessible to them. They also assess quality in relation to the availability and standard of support services such as libraries, healthcare, counselling, transport, and academic skills and technology support [11].

Academic researchers have also been very active in the higher education quality space over the last few years. As an example, Nixon [12] expresses quality in terms of 'the relation between universities and the good of society as a whole'. Over the past decade in Australia, academics have engaged extensively with quality of learning and teaching, largely as a result of the availability of project funds, initially through the Australian Learning and Teaching Council (ALTC), and more recently through the Office for Learning and Teaching (OLT). Collaboration on crossinstitutional projects has been strongly encouraged and this work has made a significant contribution to a better understanding of what constitutes quality higher education across the sector, within institutions and within discipline areas. Some of these projects have specifically addressed issues related to teaching quality, teaching standards, professionalising teaching, staff professional development and tertiary teacher preparation $[13,14,15]$.

Many leaders of these projects work in universities which have a mandatory graduate certificate in higher education teaching, or similar qualification for newly appointed staff. Some have foundations or induction programs and others have optional professional development, delivered through short face-to-face workshops and online tutorials. However, almost universally, this support is provided post-employment. As previously mentioned, universities in Australia do not require teaching qualifications as a pre-requisite for appointments to teaching positions, especially not tertiary education teaching qualifications.

Pursuing the premise that quality of higher education is substantially related to the quality of learning and teaching, this paper outlines an innovative and engaging approach to building organisational and staff capacity to lead, design and implement quality and effective learning and teaching in tertiary education for an increasingly interconnected world. The case study described is based on a successful personalised staff professional learning program that is offered through a voluntary Graduate Certificate in Education (Tertiary Teaching) (GCETT).

\section{Case Study}

The GCETT program consists of four innovative and activity-based learning courses which are studied parttime; generally one course per semester over four semesters. The program is delivered using blended learning approaches. It includes compulsory full-day faceto-face sessions, participation in learning and teaching conferences, a range of face-to-face and elective modules that incorporate digital technologies and online learning strategies, as well as workplace negotiated tasks and projects. This case study discusses the impact of this program over a four year period. The program grew from seven course enrolments ( 3 participants) in 2010 to 1177 course enrolments (355 participants) in the period 20112014.

The first course in this program introduces a range of approaches to tertiary teaching and learning using activitybased and experiential learning strategies which have their origins initially in the philosophies of Dewey [15], Piaget [16], James [17] and more recently Kolb [18] and contemporary neuroscientists and play theorists such as Brown [19]. In the first session participants collaborate in small groups and engage in a range of practical challenges. For example, some groups design, construct, cost and test miniature bridges using paddle pop sticks, drinking straws and glue. Others create games using resources from a craft box, to teach a troublesome 'threshold' learning concept from a discipline of their choice. Reconstructing essays that have been cut into dozens of pieces is a task undertaken by other groups. While a 'flip' camera presents a challenge of learning how to use the camera to record, edit and share a three minute video clip. The video task initially requires the development of a story board, prior to filming, on what each of the participants hope to achieve by doing the course.

The discussion and reflection that follows in the subsequent sessions draws out the various approaches to learning and teaching, and the embedded theories, that were experienced through these practical challenges. The participants reflect upon the differences between teachercentred, one-way transmission approaches to learning compared to activity-based, collaborative, interactive learning approaches where the student is at the centre of the learning. They discuss constructivist approaches to learning, problem-based learning, peer-to-peer learning, discovery learning, experiential learning and reflection on learning as examples of approaches which foster greater student engagement and effective learning.

In follow up sessions the participants explore, through active-learning, Aronson's [20] jigsaw strategy on 
cooperative and peer learning and discuss ways to utilise this approach to their learning and teaching settings. They also engage with the concept of the 'flipped classroom' by examining the work of Mazur [21], and Khan [22], in particular. To provide a local example, they are exposed to the work of Australian practitioner Douch [23], who actively practises and reports on his experiences in 'flipping the class' using accessible technologies to create positive, blended-learning outcomes.

Another challenge given to the participants involves learning to juggle. This activity is designed to expose learning styles and preferences. The participants document this learning 'journey' over a number of weeks and finally reflect upon how they might teach this fine motor skill to others. A website provides further details on many of the learning artefacts and activities used in this program.

Assessment in this course builds upon the various activity-based learning outcomes shared throughout the course. Participants work in groups to create posters on a key learning and teaching issue. They also begin to create their own ePortfolios to record their experiences and reflections and to source, customise and archive various learning artefacts.

The second and third courses in this certificate program consist of a range of face-to-face and online modules that utilise Moodle, Blackboard Collaborate, video conferencing and Facebook communication tools. Participants are encouraged to select modules that build upon their existing skills and knowledge and will assist them in their current learning and teaching settings. The requirement is to complete four modules in each course. Examples of modules that are offered in the second course on professional practice in tertiary teaching include topics such as: Reflective Practice; Assessment Futures (based on Boud's work) [24]; Introduction to Learning and Teaching Online; Facilitating Teaching Online, Gardner's Multiple Intelligence [25]; Introduction to ePortfolios; and, Curriculum Design and Assessment. The third course in the GCETT program explores contemporary issues in tertiary teaching. Some of the modules offered include: Interactive Learning and Teaching; Action Research; Applying for Teaching Awards; Applying for Learning and Teaching Grants; Using Social Media for Learning; 'Brain-Friendly' Learning, based on the educational resources of neuroscientist Willis [26]: and, 'Play to learn. Learn to play' which is a module that builds on Brown's [27] view that 'play is learning's partner'. Participants can also gain credit for modules in either of these courses by participating in Learning and Teaching Conference workshops.

The assessment in these middle two courses involves work on a negotiated task to address a learning and teaching issue relevant to the participant's workplace and discipline. Students often draw upon the work that they have undertaken in one or more of the modules to inspire and inform their task.

The final course in the GCETT entitled 'Tertiary Teacher as a Researcher and Practitioner' builds on the work in the three previous courses and allows the participants to undertake a personalised negotiated project relevant to them. This experience provides exposure to current practice in the scholarship of learning and teaching and to a suite of approaches to researching teaching practice. The outcomes from these projects are presented as draft journal articles, video or narrated conference presentations or a fifteen minute oral presentations. Typical project themes from previous semesters include: 'Transition to higher education'; 'Teaching and curriculum development'; 'Focus on learners and students'; 'Higher Education and industry collaboration'; 'Learning and disadvantaged groups'; 'New technologies in the teaching space'; and, 'Innovative learning methods.

The impact of the teacher on the learning experience and outcomes of students has been widely recognised for some time [28]. This is evident across all educational sectors from early childhood to higher education. One of the first activities we do in the GCETT is to ask the participants to reflect upon an extremely positive or an extremely negative educational experience. This activity is used as a catalyst for further discussion on issues and questions such as: 'What factors contribute to a quality learning experience?'; 'What are some of the impediments or barriers to effective learning?'; 'What role does the teacher play in providing quality learning?'; and, 'What attributes and skills does an effective teacher need?'.

\subsection{Approach}

The GCETT has been purposefully designed to enable participants to personalise and shape their learning throughout the program to meet their specific knowledge, skills and context requirements. The program is informed by a number of learning theories. In particular, it links contemporary, evidenced-based information from neuroscience on how the brain learns to activity-based learning utilising games and play as a mode of engagement, learning and knowing. The work of Willis [28], a former clinical neuroscientist and now practising educator, who discusses the importance of 'brain-friendly' learning strategies is drawn upon. The program is also heavily influenced by the contribution of 'play' to learning and development promoted in the research and publications of neuroscientist Brown [30]. The outcomes of this approach are powerful. The feedback and evidence from participants and supervisors is that the program is changing teaching practice and contributing substantially to the quality of higher education across the University and partner sites.

In order to reinforce the underlying theoretical principles in the GCETT, and to assist recall and implementation, the key features of the program are playfully linked through an alliteration technique using words that commence with the letter ' $\mathrm{C}$ '. Each of these words aligns with and is reinforced in the research of Willis and Brown and is validated by other neuroscientists.

Capacity building of individuals, 'communities of practice' and organisations is a primary driver for the GCETT. Throughout the four courses the participants are constantly encouraged to grow their knowledge and skills by being exposed to a diverse range of literature, videos, panel discussions, learning activities and leading learning and teaching scholars. Peer-to-peer learning is facilitated through informal and formal learning activities and often the learner becomes the teacher and the teacher becomes the learner. The idea of multiple forms of stimulation is supported by the science of learning through the work of Willis [35] and many other neuroscientists [36,37]. 
Multiple forms of stimulation foster interest, engagement and cater for preferred learning styles.

Customisation is also fundamental to the GCETT's approach. Participants are encouraged to relate learning from the case studies and learning activities presented in the sessions to their particular workplace. For example, this work may take place in a library, in a large, single discipline undergraduate program, in a small, higher degree research course or across a number of teaching sites. The negotiated tasks, which sit within the two middle courses in the program, provide opportunities for participants to investigate and to address a 'real' issue in their workplace. Other participants use the negotiated task as an opportunity to develop learning resources or learning activities to help clarify a threshold or troublesome learning concept within a course they are currently teaching. The value of customising learning is supported by findings from the science of learning that suggests the provision of positive, non-threatening learning environments minimises the potential for stress, frustration or boredom [38].

Contextualisation is another key consideration that underpins the GCETT program. This is primarily achieved by emphasising a student-centred approach to teaching. From day one, the importance of understanding the context, culture and skill levels of the diverse learners within courses the participants teach, is emphasised. Fundamental to this approach, is a belief that if you are to actively engage your students in learning; you need to have an understanding of their prior learning experiences, their current skill levels and what interests them. Participants in the GCETT are encouraged to interpret case studies and issues from various cultural perspectives to reinforce the importance of considering issues from various viewpoints. Findings from the science of learning refer to barriers or impediments to learning which prevent information passing into the processing areas of the brain [39]. Providing learning activities which are far beyond the skill and knowledge levels of the learner will trigger 'blockers', as will providing learning activities which are too basic or boring for the learner.

Collaboration and cooperative learning is encouraged throughout the GCETT. In the workplace participants primarily work in teams and their collaborative efforts generally result in better outcomes. This principle is modelled and practised in the program. Participants are encouraged to undertake partner or group learning activities to illustrate the value of collaboration. Various activities in the GCETT are specifically designed to demonstrate the multiplying effect of working together to solve problems to difficult teaching situations. Collaborative writing is also encouraged as is peer-to-peer mentoring by reading colleagues' draft papers. The value of collaborative and cooperative learning is supported by the science of learning. Willis [39] identifies team activities as one of the 'brain-friendly' learning strategies that facilitates memory and higher order thinking (executive thinking).

Creativity is experienced in a number of ways throughout the GCETT. One example is the game development activity, where the participants are given a box of assorted craft items and asked to develop an ageappropriate game to introduce, reinforce or assess a key knowledge or skill concept which could be used in their teaching or workplace. Another example is where the participants are required to prepare a tangible artefact that depicts a key word to describe their philosophy of teaching. This simple activity is very effective in helping participants identify what they are trying to achieve in their teaching. The research of neuroscientist Brown [40] is particularly relevant when considering the value of providing opportunities for play and creativity for learning and innovation.

Choice and flexibility are frequently identified as positive elements of the GCETT in participants' feedback and reflections. As indicated previously, staff are encouraged to shape their learning to suit their requirements. The GCETT provides many opportunities for this to occur. In the poster task participants can elect to investigate any topic within a student, teacher, learning and teaching quadrant. The middle two courses in the GCETT enable participants to select modules of study from a range of face-to-face and online offerings. They can choose modules based on areas of interest, need or convenience. Many of the participants also work full-time and have family and other responsibilities, so travel to onsite sessions and workshops is not always convenient. However, it is worth noting that attendance levels at faceto-face sessions are high and feedback is consistently positive. Therefore, we would be reluctant to remove faceto-face engagement from the program. The value of providing choice and flexibility is another 'brain-friendly' learning strategy identified by neuroscientists, including Willis [41].

Continuous improvement, primarily through reflective practice and the provision of timely and accurate feedback is critical to sustaining engagement and achieving incremental improvements in teaching practice throughout the GCETT.Although staff regularly use online discussion forums and other means of providing informal feedback, the participants constantly ask for more feedback. Coincidently, that is exactly what staff report their students comment upon. Self and peer assessment is also practised to develop skills in analysis, judgment and giving and receiving constructive feedback. The value of regular feedback, rehearsal and positive reinforcement are identified as important practices for learning in findings from the science of learning. Willis [42] refers to the importance of incremental learning and mastery of knowledge and skills for moving information from short term to long term memory to enable higher order thinking.

Connectivity is important for developing higher order thinking skills such as analysis, problem solving, divergent thinking and innovation. The team that delivers the GCETT work very closely to ensure that connections between various modules and courses are made explicit and reinforced. For example, study of assessment futures is directly linked to modules on curriculum design and learning outcomes. The modules on action research inform work undertaken in the negotiated tasks, and skills acquired in the reflections on teaching module, are drawn upon throughout the program. The value of connectivity and relationship and pattern building is supported by the science of learning, particularly in discussions on brain plasticity and growth, and application and retrieval of information [44].

Communication through multiple modes is practised throughout the program. Online learning is mainly managed and delivered through Moodle, but Blackboard Collaborate, Skype and video conferencing are also 
introduced. Each year, at least one, two-day learning and teaching conference is held at the main campus. These events have been extremely well supported and have given the GCETT participants exposure to leading national learning and teaching scholars, as well as opportunities to share their practice with colleagues. From the point of view of the science of learning, using a range of modes of communication is acknowledged as an important learning strategy. Willis [45] extends this to strategies such as 'being read to', 'listening to music' and 'humour'.

Challenge in the GCETT is linked to the concept of incremental learning. The aim in the GCETT is to provide participants with progressive challenges that are within their skill level and knowledge, but provide opportunities to stretch and grow their capacity. The utilisation of ePortfolios in the GCETT is an example where participants are challenged to progressively demonstrate growth in ability. As they progress through the program they are expected to upload to their digital portfolios more advanced reflections and learning artefacts using audio, video, graphics and photographic images. Participants are also challenged throughout the program to grasp new knowledge and learn new skills. Providing opportunities for celebrating achievement and progress is at the forefront of this program. Small and incremental successes and achievements are recognised and reinforced by the GCETT team and shared with colleagues. The value of providing attainable challenges for fostering learning is reinforced by the science of learning. Willis [46] discusses the need for opportunities for learners to experience success and how the brain releases dopamine which provides a natural 'high' and reinforces positive behaviour.

Contemporary research, theory and technologies are drawn upon in the GCETT to ensure that the professional learning provided to staff is relevant and cutting edge. The program utilises current national and international scholarship of learning and teaching scholars, research and literature. In Australia, over the past decade the government has provided substantial funding for learning and teaching projects in higher education which has led to a wealth of information and data that participants can refer to and build upon in their projects. Modules on the effective use of social media for learning and the exposure to emerging technologies also ensure that the program stays fresh and contemporary. Through these modules participants develop the requisite skills to interact with and engage contemporary learners. The science of learning affirms the value of practical activities and opportunities to link theory through practice for developing higher order thinking skills such as analysis, problem solving and decision making [47].

Changing awareness, attitudes, and behaviour is at the heart of this staff professional learning program. The purpose of the program is to widen the participants' understanding of what is means to be an effective teacher and to develop approaches to learning and teaching which motivate, influence and engage students in learning. For the early career participants, it is about helping to shape their teaching philosophy and providing them with effective learning and assessment tools. For the more experienced teachers, it is about stretching them beyond their comfort zone. It is about encouraging them to explore and utilise emerging technologies, to share their learning and practice with colleagues, and to continually reflect upon the impact of their teaching on the student learning experience and outcomes.

\section{Findings}

The key findings from this Case Study were primarily identified in the shifts in thinking and teaching practice reported by the various stakeholders. These shifts were captured in the participants' ePortfolio reflections and postings. They have also been sourced from assessment artefacts such as: group posters; negotiated tasks and projects; and, from formal and informal feedback from staff supervisors and managers. The external evaluator for the project has also provided independent feedback and critical analysis which has informed the program.

The following list is not necessarily exhaustive. However, it describes some of the main impacts and benefits of the program identifed over the past four years of delivery of the GCETT in its current form.

\subsection{Impact}

A shift from teacher-centred approaches to learner and learning-centred approaches was frequently reported by the participants. 'Perhaps the biggest improvement I have seen in my teaching is the shift from the two dimensional lecture type classes to the interactive, project based learning environment'.

Reinvigoration of teaching staff and a renewed interest in learning and teaching was another outcome commented upon by many of the participants over the past four years. 'The ePortfolios and a number of tasks, especially the group poster, allowed a high degree of creativity and design which I found fun and motivating'.

Exposure to innovation and creativity in reconceptualising learning and assessment activities throughout the course of the GCETT encouraged staff to try new approaches in their own teaching. 'As I sit and write this reflection, I feel quite humbled at my own ability and the final product I am (about) to submit. I have looked back over my ePortfolio and ... am quite amazed at what I have achieved'.

There was also evidence among the staff of greater application of learning and teaching theory and research to inform practice. 'I have particularly enjoyed extending my knowledge and understanding of applying educational research practices to ensure positive teaching and learning outcomes, whilst gaining increased knowledge of how to best monitor and evaluate learning and teaching performance.'

Staff frequently reported an increase in self-esteem and belief in ability to enhance student learning. 'This course has provided me with the connections to educational theory and given me more confidence when participating in pedagogical discussions.'

Improved self-confidence and skill level in the use of technologies to facilitate learning has been a valuable outcome for participants in this course. 'The focus on the use of social media technologies to support learning was of great benefit to me in continuing to refine my teaching and assessment methods so that they are relevant, current and meaningful to the student.'

Staff often experience difficulty in finding time to collaborate and share teaching practices. This program 
provided such an opportunity and established a pattern for future practice. 'I also enjoyed the personal support and the interaction with staff and other students and the opportunities that came about from the program.'

Integration of library staff into discussions about learning and teaching through opportunities to participate in the program and related professional development was an unforeseen outcome and benefit of the program. Library staff report that this has been a wonderful opportunity for them and they are currently trialing some links to their online resources from the GCETT Moodle site.

Several senior managers and staff reported an improved tone and culture within their workplaces. 'Staff room conversations now include discussions about teaching approaches and strategies. Staff are no longer operating in silos.'

Greater connections with community, industry and business groups across the sites resulted from many of the negotiated tasks and projects. One example came about through a partner-based activity which matched an earlychildhood teacher with an aged-care services teacher. The outcome is an ongoing project on intergenerational learning that has already resulted in a small grant and a trip to the United States of America to visit centres which combine early childhood and aged-care services.

A completely unanticipated outcome from the GCETT is a desire from a number of participants to continue with higher degree studies. Approximately one in five staff have expressed interest in undertaking further study in education, mainly Master of Education degrees and $\mathrm{PhD}$ programs, as a result of being reenergised through their GCETT studies.

In addition to the extensive qualitative feedback available on the impact and quality of the GCETT program, a range of quantitative data provides further evidence of the value of the program. Since the refreshed program was introduced in 2011, staff participation has grown from 7 course enrolments in 2009-2010 to 1177 course enrolments (355 participants) in the period 20112014. This includes 180 University partner staff through a major state government grant.

Grade distribution over the duration of the program also demonstrates improved engagement and quality of the learning outcomes. In the final course of the program the percentage of participants who received a Higher Distinction (HD) grade is consistently higher than in the first course of the program. (2011 cohort one, $8 \%$ HDs in course one, $75 \%$ in the final course. 2011 cohort two, $12 \%$ HD in the first course, $38 \%$ in the final course. 2012 first cohort $11 \%$ HDs in the first course, $36 \%$ in the final course and in the second cohort $28 \%$ HDs in the first course and $53 \%$ in the final course). While a number of factors may be contributing to this improvement in performance, it does point to sustained engagement with the program and the production of worthwhile assessment artefacts, and demonstration of learning outcomes in the final course.

The following excerpt from the external evaluator highlights the impact and staff enrichment provided by the GCETT.

'Since the beginning of the program I have observed with interest the growth of the participants from nervous novices to confident and rigorous scholars of learning and teaching. I have been impressed by the strength of a program that allows people to develop at their own pace whilst facilitating and promoting networking and collaboration. At the core of this program is the notion of play as a serious area of scholarship. An initial activity around learning to juggle became a metaphor for a variety of activities - the acquisition of metacognitive skills, a deeper understanding of the different ways in which students learn, and the juggling of time between work, study and life.'

\section{Discussion and Conclusion}

The key premise explored in this paper is that the quality and effectiveness of the teacher has a great impact upon the quality of the student experience and learning outcomes and subsequently the quality of higher education This case study is presented as an illustration of how innovative, flexible and interactive staff professional learning can substantially build staff and organisational capacity to improve quality learning and teaching. The findings identified a number of positive shifts in practice as a result of participating in this staff development program. These included: a shift from teacher-centred approaches to learner and learning-centred approaches; reinvigoration of teaching staff and renewed interest in learning and teaching; evidence of innovation and creativity in reconceptualising learning and assessment activities; and, greater application of learning and teaching theory and research to inform practice.

The findings also reinforced the value of the approach, previously outlined in this paper, that was used to build the capacity of early career tertiary education teachers and to re-energise mid-career tertiary teachers who may have become a little staid in their teaching. The adoption of the ' $C$ ' words: customisation; contextualisation; collaboration and cooperative learning; creativity; choice; continuous improvement; connectivity; communication; challenge; contemporary and change in awareness, attitudes and behaviour served as a framework for the program, was compatible with sound professional learning principles and practice and also aligned with the diverse needs of the participants. Using this alliteration technique also acted as a simple recall prompt. Staff were given the freedom and flexibility to shape their own professional learning and development journey. This ability greatly contributed to the positive engagement and retention of the participants.

While the findings from this case study report a number of benefits of this type of personalised staff professional learning experience, it also raises some further questions for consideration. These include: 'When should such a program be offered to university staff; pre or post appointment?' and 'Should a tertiary education teacher qualification be mandatory or voluntary for a teaching appointment in a university?'

In the final analysis of this case study, it is difficult not to conclude that if we are going to be truly genuine about ensuring the quality of higher education, we need to give serious thought to mandating that teachers have appropriate tertiary teacher education preparation. This does not seem like a big impost or indeed a remarkable recommendation. Relevant and certified teaching qualifications for teachers have been a requirement in all other education sectors from early childhood through to Vocational Education and Training for some time. The academy has been slow in recognising or at least 
accepting that a great mathematician or bio-chemist does not necessarily make a great teacher. Or put another way: think how much better the great mathematician's teaching and engagement with students could be if they had some background and experience in the scholarship of learning and teaching. It is not unreasonable to suggest that the default approach of 'teaching the way I was taught' in higher education is doing our students a great disservice and needs to be challenged.

This case study found that a number of benefits and positive shifts in practice resulted from the professional learning offered to staff through a formal tertiary teaching qualification. While it did not specifically answer the question: 'What is the impact on the quality of higher education of not requiring our teaching staff to have a tertiary teacher education qualification as a pre-requisite for employment?', it did illustrate and demonstrate, with evidence, the substantial benefits to the overall quality of higher education that can be achieved as a result of a providing a personalised, relevant and flexible tertiary teaching qualification such as the one outline in the reported case study. Teaching the way I was taught? Not anymore!

\section{References}

[1] Australian Government Tertiary Education Quality Agency, About TEQSA. Available: http://www.teqs a.go v.au/abo ut [Accessed 1 Sept. 2014].

[2] Australian Government Tertiary Education Quality Agency, Highereducation standards framework. Available:

http://www.teqsa.go v.au/higher-educ ation-standards -framework [Accessed 1 Sept. 2014].

[3] Australian Qualifications Framework Council, Second Edition January 2013. Available: http://www.aqf.edu.au/ [Accessed 1 Sept. 2014].

[4] Australian Government Higher Education Standards. Higher Education Standards Panel, Communique Number 11, June 2014. Available:;

http://www.hestandards.gov.au/sites/default/files/Com muniqueNumber11-HEStandards.pdf [Accessed 1 Sept. 2014].

[5] Academic Quality Agency for New Zealand Universities. Quality Enhancement. Available:

http://www.aqa.ac.nz/about-us/aqa [Accessed 1 Sept. 2014].

[6] The UK Professional Standards Framework for teaching and supporting learning in higher education 2011. Available: https ://www.he fce.ac.uk/media/he fce/content/abo ut/staffands truct ure/board/2011/142/B83b.PDF [Accessed 1 Sept. 2014].

[7] Universities Australia. Public Perceptions of Australia's Universities (2013). Available: http://apo.org.au/files/Resource/UniversitiesAustralia_PublicPerce ptionsUniversities_February2013.pdf [Accessed 1 Sept. 2014].

[8] Lipsett, A. Parents want children to get higher education they missed. the guardian.com (2008) Available:

http://www.theguardian.com/education/2008/nov/06/regreteducation-delay [Accessed 1 Sept. 2014].

[9] Graduate Careers Australia. What Employers Want. Available: http://www.graduatecareers.com.au/CareerPlanningandResources/ StartingYourSearch/GraduateSkillsWhatEmployersWant/inde x.ht m [Accessed 1 Sept. 2014].

[10] Leadership and Management of Quality in Higher Education Edited by Nair, C.S., Webster, L and Metova, P. Chandos Publishing, Oxford, 2010.

[11] The University of Queensland Australia, Office of Marketing and Communications. What do future students want? Available: http://www.uq.edu. au/omc/june-futurestude ntsadvice. [Accessed 1 Sept. 2014].

[12] Nixon, J. Higher Education and the Public Good: Imagining the University. Continuum International Publishing Group, London, 2011.
[13] Australian Government, Office for Learning and Teaching. Professionalisation of the academic workforce project. Available: http://www.olt.gov.au/project-professionalisation-academicworkforce-project-2012 [Accessed 1 Sept. 2014].

[14] Australian Government, Office for Learning and Teaching. Beyond numbers: valuing quality teaching in business education. Available:

http://www.olt.gov.au/project-be yo nd-numbe rs- valuing-quality-cs u-2008 [Accessed 1 Sept. 2014].

[15] Dewey, J. Experience and Education, Touchstone, New York, 1938 (1997 edition).

[16] Piaget, J. Play, Dreams and Imitation in Childhood, Norton, New York, 1962.

[17] James, W. The Writings of William James: A Comprehensive Edition, Edited with and Introduction by John J. McDermott, University of Chicago Press, Chicago 1977.

[18] Kolb, D.A, Experiential Learning: Experience as the Source of Learning and Development, Prentice-Hall, Inc., Englewood Cliff. N.J., 1984.

[19] Brown, S. Play: how it shapes the brain, opens the imagination and invigorates the soul, Scribe Publications Pty Ltd, Carlton North, Australia, 2009.

[20] Aronson, E. Nobody left to hate: Teaching compassion after Columbine, W. H. Freeman, New York, 2000.

[21] Mazur, E. Confessions of a Converted Lecturer. Available at: https://www.youtube.com/watch?v=WwslBPj8GgI [Accessed 29 Sept. 2014].

[22] Khan, S, Let's use video to reinvent education. Available at: http://www.ted.com/talks/salman_khan_let_s_use_video_to_reinve nt_education [Accessed 29 Sept. 2014].

[23] Douch, A. Flipping the classroom. Available at: http://andrewdouch.wordpress.com/2011/11/14/flipping-theclassroom/ [Accessed 29 Sept.2014]

[24] Boud, D. Assessment Futures. Available at: http://www.uts.edu.au/research-and-teaching/teaching-andlearning/assessment-futures/overview [Accessed 20 Sept. 2014].

[25] Gardner, H, Multiple intelligences: New Horizons in Theory and Practice, Basic Books, USA. First edition 1993, revised and updated 2006

[26] Willis, J. Research-based strategies to ignite student learning, ASCD, Alexandria, 2006.

[27] Brown, S. Play: how it shapes the brain, opens the imagination and invigorates the soul, Scribe, Australia and New Zealand, 2010, 101.

[28] Australian Government, Office for Learning and Teaching. Measuring and reporting teaching quality. Available: http://www.olt.gov.au/project-measur ing-and-reporting-teachingquality [Accessed 1 Sept. 2014].

[29] Hattie, J. "Teachers Make a Difference: What is the research evidence?" Australian Council for Educational Research Annual Conference on: Building Teacher Quality. University of Auckland October 2003. Available:

http://www.educ ationalleade rs.go vt.nz/Pedago gy-andassessment/Building-effective-learning-environments/Teachers-

Make-a-Difference-What-is-the -Research-Evide nc e [Accessed 1 Sept. 2014].

[30] Willis, J. Research-based strategies to ignite student learning, ASCD, Alexandria, 2006.

[31] Brown, S. Play: how it shapes the brain, opens the imagination and invigorates the soul, Scribe, Australia and New Zealand, 2010.

[32] Arrowsmith-Young, B. "The woman who changed her brain". ACER Research Conference, How the Brain Learns: What lessons are there for teaching? 2013, 7-15.

[33] della Chiesa, B. "Our Learning/Teaching Brains: What can be expected from neuroscience, and how? What should be expected from neuroscience and why?" ACER Research Conference, How the Brain Learns: What lessons are there for teaching? 3-6.

[34] Doidge, N. The Brain That Changes Itself: stories of personal triumph from the frontiers of brain science, Published in Australia and New Zealand by Scribe, 2010.

[35] Howard-Jones, P. "Minds, Brains and Learning Games". ACER Research Conference, How the Brain Learns: What lessons are there for teaching? 16-23.

[36] Willis, J. Brain-Friendly Strategies for the Inclusion Classroom, ASCD, Alexandria, 2007.

[37] Sousa, D. How the brains learns, Thousand Oaks, Corwin, 2011. 
[38] Sousa, D. (Editor) mind, brain, \& education: Neuroscience Implications for the Classroom, Solution Tree Press, Bloomington, 2010.

[39] Willis, J. Brain-Friendly Strategies for the Inclusion Classroom ASCD, Alexandria, 2007, 43-47.

[40] Willis, J. Research-based strategies to ignite student learning, ASCD, Alexandria, 2006, 56-73.

[41] Willis, J. Research-based strategies to ignite student learning, ASCD, Alexandria, 2006, 75-101.

[42] Brown, S. Play: how it shapes the brain, opens the imagination and invigorates the soul, Scribe, Australia and New Zealand, 2010, 73 .
[43] Willis, J. Brain-Friendly Strategies for the Inclusion Classroom, ASCD, Alexandria, 2007, 108-113.

[44] Willis, J. Brain-Friendly Strategies for the Inclusion Classroom, ASCD, Alexandria, 2007, 114-120.

[45] Sousa, D. How the brains learns. Thousand Oaks, Corwin, 2011, 113-116.

[46] ABC Big Ideas, Optimising Our Potential. Available: http://www.abc.net.au/tv/bigideas/stories/2010/11/30/3079463.htm [Accessed Sept 1, 2014].

[47] Willis, J. Brain-Friendly Strategies for the Inclusion Classroom, ASCD, Alexandria, 2007, 26, 71-75,103-104.

[48] Willis, J. Research-based strategies to ignite student learning, ASCD, Alexandria, 2006, 70 . 